

\title{
Physico-chemical and mechanical degradation of polyamide 11 induced by hydrolysis and thermal ageing
}

S. Maïza, X. Lefebvre, N. Brusselle-Dupend, M.-H. Klopffer, L. Cangémi, S. Castagnet, J.-C. Grandidier

\section{- To cite this version:}

S. Maïza, X. Lefebvre, N. Brusselle-Dupend, M.-H. Klopffer, L. Cangémi, et al.. Physico-chemical and mechanical degradation of polyamide 11 induced by hydrolysis and thermal ageing. Journal of Applied Polymer Science, 2019, 136 (23), pp.47628. 10.1002/app.47628 . hal-02180807

\section{HAL Id: hal-02180807 \\ https: / hal-ifp.archives-ouvertes.fr/hal-02180807}

Submitted on 11 Jul 2019

HAL is a multi-disciplinary open access archive for the deposit and dissemination of scientific research documents, whether they are published or not. The documents may come from teaching and research institutions in France or abroad, or from public or private research centers.
L'archive ouverte pluridisciplinaire HAL, est destinée au dépôt et à la diffusion de documents scientifiques de niveau recherche, publiés ou non, émanant des établissements d'enseignement et de recherche français ou étrangers, des laboratoires publics ou privés. 


\title{
Physico-chemical and mechanical degradation of polyamide 11 induced by hydrolysis and thermal ageing
}

\author{
S. Maïza ${ }^{1,2,{ }^{*}}$, X. Lefebvre ${ }^{1}$, N. Brusselle-Dupend ${ }^{1}$, M-H. Klopffer ${ }^{1}$, L. Cangémi ${ }^{1}$, S. Castagnet ${ }^{2}$, J-C. \\ Grandidier ${ }^{2}$ \\ ${ }^{1}$ IFP Energies nouvelles - 92500 Rueil-Malmaison \\ 2 Institut PPRIME, ENSMA - 86360 Chasseneuil-du-Poitou \\ Correspondence to: Sofiane Maïza (Email: maiza.sofiane@gmail.com)
}

\begin{abstract}
This paper deals with the effect of both temperature and water activity on polyamide 11 physicochemical and mechanical properties.

The purpose of this work is to describe the ductile-brittle transition of polyamides during ageing in a wet environment using a mechanical behavior model. For that it is necessary to make physico-chemical analyzes (DSC, FTIR, GPC, viscosity) and mechanical tests (uniaxial tensile test and DMTA). These characterizations were carried out on safe and samples aged until 60 days under hydrothermal conditions in acid water, and under purely thermal conditions in a neutral environment. Changes in mechanical properties with ageing were observed in the polymer and were correlated to morphological changes deduced from the physicochemical characterizations. An increase of the second yield stress related to the recrystallization and a decrease of the strain at break due to the decrease of the molecular weight were observed during ageing.
\end{abstract}

\section{INTRODUCTION}

In many fields of industry, semi-crystalline polymers are used as protective coatings because of their barrier properties and their flexibility. They have high barrier properties to liquids and gases. The use of this material is only selected if their long-term durability is clearly demonstrated, under conditions similar to the intended use. Semi-crystalline thermoplastic polymers have been intensively studied over in recent decades to understand and predict their mechanical behavior. Depending on the nature of the polymer, the presence of water and temperature may have several effects on its mechanical behavior such as recrystallization ${ }^{1-4}$, plasticization ${ }^{5,6}$ or ageing $^{7-10}$.

PA11 is used extensively in hydrocarbon transport pipes. This polymer is one of the many layers present in the pipe. Regarding polyamides, the presence of hydrogen bonds in their macromolecular chains makes these semi crystalline polymers hydrophilic and particularly sensitive to chain scissions mechanism in presence of water, also communally called hydrolysis. Indeed, the amide group (-CONH-) reacts chemically with water, which will create an acid group and an amine group. Many authors have characterized hydrolysis in polyamides $3,11,4,12$ through a drop in molecular weight, and an acceleration of the chain scission mechanism has been observed in an acid ageing environment associated with high temperature. It is generally stated that water intake in the material is governed by a Fickian diffusion 

when ageing is very long. The authors assumed that this water excess is present as aggregates inside the material.

From a mechanical point of view, the hydrolysis of the macromolecular chains in the amorphous phase results in a drop in the strain at break, which leads to embrittlement of the material ${ }^{14}$. Moreover, high temperature generally used to accelerate hydrolysis in laboratory involves an annealing process at the origin of a raise of the plastic yield ${ }^{15-17}$.

Few studies have shown the role of temperature only on the mechanical behavior of PA11 during longterm ageing, and others on accelerating the chemical reaction. However physical ageing and chemical ageing may have cumulative or opposite effectst is therefore difficult to isolate the impact of each isolated mechanism. More precisely, water diffusion causes the material to swell and plasticize during the ageing process. Water plasticization is partly responsible for the ductile behavior of the polymer. At the same time the water also reacts chemically with the polymer by hydrolysis reaction which results in its embrittlement. All these phenomena are temperature dependent.

The coupling of all phenomena made it very difficult to understand the effect of chemistry on the macromolecular chains and the mesostructure in order to conclude consequences on the mechanical properties. On the other hand, correlating the evolutions of the physico-chemical parameters expressing the chemical modifications and the mechanical properties permits to understand and dissociate the effects of temperature and hydrolysis, and supports a coupled modelling at the macroscopic scale.

To this aim, it is proposed to conduct a comparative study of mechanical tests on different samples: healthy specimens aged under water and in dry atmosphere. This comparative study aims to describe the links between physicochemical and mechanical descriptors. Ageing is carried out in water, under pressure of $\mathrm{CO}_{2}$ in order to reach $\mathrm{pH}$ 4. Thermal ageing in an inert medium $\left(\mathrm{N}_{2}\right)$ will enable to uncouple pure thermic effects from hydrolysis effects. For each ageing protocol, physicochemical characterizations and mechanical tests are carried out to follow the evolution. Finally, results are analyzed to demonstrate the relationships between the PA11 microstructure evolution during ageing and its macroscopic mechanical behavior.

\section{EXPERIMENTAL}

The material under study is the PA11 Rilsan ${ }^{\circledR}$ BESNO TL+ grade from Arkema. The melting temperature is around $190^{\circ} \mathrm{C}$. The material contains $0.8 \%$ by weight of antioxidant. It was extruded at $220^{\circ} \mathrm{C}$ to form 1.5 - $2 \mathrm{~mm}$-thick tapes, in order to limit ageing gradient in the thickness. In order to avoid cumulating other physical effects, the choice was focused on plasticizer-free material in order to facilitate the analysis of the results from the tests. Tensile specimens were punched out from these belts to perform the mechanical tests, as well as circular pellets for different physicochemical analyzes. 


\section{Choice of ageing conditions}

The ageing conditions were chosen so that the duration was short enough to be representative and sufficiently slow to observe a progressive evolution of the mechanical behavior. Ageing were performed inside hermetically sealed autoclaves. The volume of each autoclave was about 1 litre. In order to accelerate hydrolysis, the ageing was carried out at $110^{\circ} \mathrm{C}$ and a $\mathrm{CO}_{2}$ pressure of 21 bars was imposed in order to reach $\mathrm{pH} 4$ in Volvic $^{\circledR}$ water. To prevent oxidative degradation processes, the water was previously deoxygenated by bubbling with pure nitrogen gas $\mathrm{N}_{2}$ during more than $18 \mathrm{~h}$. This kind of ageing associates diffusion of water $(W)$, hydrolysis $(H)$ and temperature $(T)$ called $(H+T+W)$ when combined. After ageing, in order to pass over the plasticizing effect of water, the samples were dried for 30 days under vacuum at $40{ }^{\circ} \mathrm{C}$. These samples are called $(\mathrm{H}+\mathrm{T})$ samples. In order to uncouple temperature and hydrolysis effects, a pure thermal ageing was carried out in the same hermetically sealed reactors at $110^{\circ} \mathrm{C}$, but with an inert atmosphere of pure nitrogen at a pressure of 4 Bars. These samples were called $(T)$ samples. Note that before ageing, samples were dried for 30 days under vacuum at $40^{\circ} \mathrm{C}$ to avoid any water or oxygen inside the material. All ageing conditions are shown in Table 1.

After dedicated ageing, $\mathrm{H}+\mathrm{T}$ and $\mathrm{T}$ samples were stored in a desiccator to avoid water uptake at the atmosphere. Moreover, they were stored in the dark to avoid photo-oxidative decomposition.

\begin{tabular}{|c|c|}
\hline Ageing conditions & Samples designation \\
\hline $110^{\circ} \mathrm{C}$ under azote & $\mathrm{T}$ \\
\hline $\mathrm{pH} 4 / 110^{\circ} \mathrm{C}$ satured by water & $\mathrm{H}+\mathrm{T}+\mathrm{W}$ \\
\hline $\mathrm{pH} 4 / 110^{\circ} \mathrm{C}$ and drying for 30 days & $\mathrm{H}+\mathrm{T}$ \\
\hline
\end{tabular}

Table 1 Ageing conditions and samples designation

\section{Samples preparation}

In order to characterize the mechanical behavior of the virgin material, it was necessary to dry it with the aim of extracting the initial water content and to get rid of its plasticizing effect.

The amount of water initially present in the material was determined by drying below Tg (to avoid disturbing the structure of the material) and under vacuum. Samples were regularly weighted until stabilization, i.e. after 27 days in our case as shown in Figure 1. The material exhibited an almost Fickian behavior. It could be deduced from this figure that the fraction of water present in the virgin control material was $0.5 \%$.

The mass fraction was calculated as follows:

$\frac{(m 0-m 0 s)}{m 0}$ 
with $m_{0 s}$ the mass of the control sample in a "dried" state, i.e. without water. $m_{0 s}$ was measured from the asymptotic state.

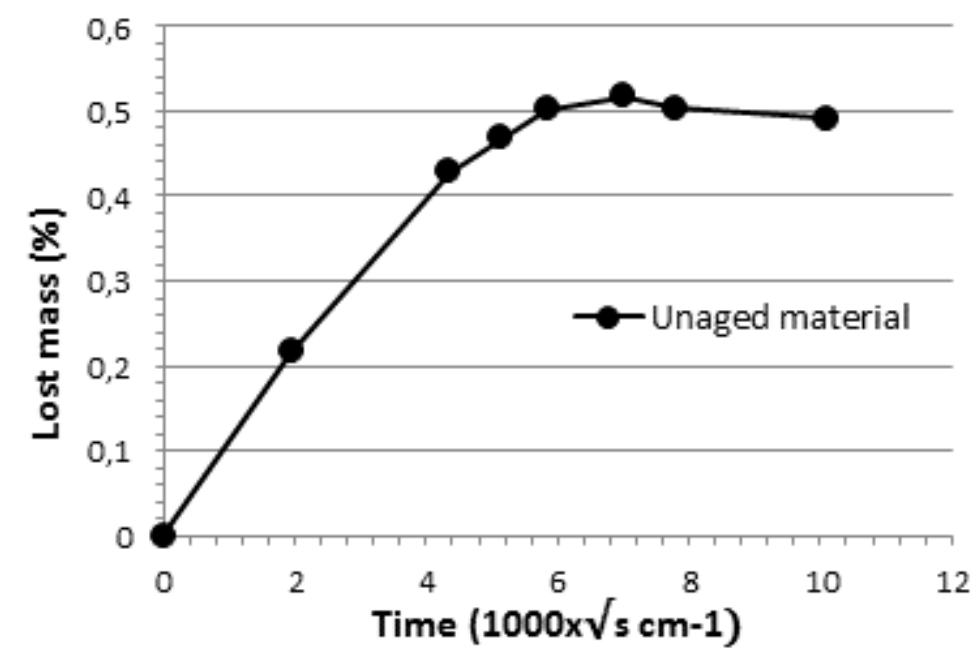

Figure 1 Weigh loss during drying at $40^{\circ} \mathrm{C}$ under vacuum of blank test specimens

In order to assert that the loss of mass was linked to water, the water content was measured by Karl Fischer technique in as received and 27-day dried samples (each condition being repeated three times). In order to extract as much water as possible, the sample was heated to $140^{\circ} \mathrm{C}$ during Karl Fischer analysis. Results were reported in Table 2. It appears that despite drying, there was still some water in the PA11. This phenomenon has already been observed in PA6 and was justified by the strong interaction of hydrogen bonds between water and $\mathrm{CONH}$ groups ${ }^{18}$.

\begin{tabular}{|c|c|c|}
\hline & PA11 not dried & PA11 dried for 27 days at $40^{\circ} \mathrm{C}$ \\
\hline Water content & $0.76 \% \pm 0.05$ & $0.33 \% \pm 0.02$ \\
\hline
\end{tabular}

\section{Differential Scanning Calorimetry (DSC) conditions}

DSC analyses were performed on a Mettler Toledo system with nitrogen as purge gas. For each sample, approximately $12 \mathrm{mg}$ was weighed, placed in a non-hermetic aluminum cup, and analyzed with the following program. 2 cycles of heating and cooling are carried out. The heating rate is $10^{\circ} \mathrm{C} \cdot \mathrm{min}^{-1}$ up to $250^{\circ} \mathrm{C}$ and the temperature is maintained for $5 \mathrm{~min}$. Then, the cooling rate is identical up to $20^{\circ} \mathrm{C}$ and is maintained for $5 \mathrm{~min}$.

\section{Gel Permeation Chromatography (GPC) and Rheological characterization}

The evolution of chain cuts has been followed by two different characterization techniques: Gel Permeation Chromatography (GPC) and rheological measurements.

Molecular mass is measured using GPC. The principle consists in introducing a diluted solution of the polymer into a column. Because of the difference in size, large macromolecules cannot penetrate while 
small macromolecules diffuse freely. Calibration is done in PMMA standards, since it is necessary to calibrate the instrument with known molecular weight standards. The molecular weight of PA11 is obtained by indirect measurement. Indeed, the molecular weight of PMMA is calculated before deducting the mass of PA11. Approximately $20 \mathrm{mg}$ of PA (annealed $1 \mathrm{~h}$ at $80^{\circ} \mathrm{C}$ ) are added to $2 \mathrm{ml}$ of $\mathrm{CH}_{2} \mathrm{Cl}_{2}$ sec. A large excess of ATFA (about $2 \mathrm{mg}$ ) is introduced. After 24 hours of agitation, a clear solution is obtained. The solvent, the excess ATFA and the acetic acid formed are evaporated under vacuum. The mixture is solubilized in $2 \mathrm{ml}$ of $\mathrm{CH}_{2} \mathrm{Cl}_{2}$ and analyzed by steric exclusion chromatography.

In order to compare and confirm the molecular mass measurements, viscosity measurements were done. The instrument is a TA instrument DHR3 rheometer and the software is Trios. The details of the test conditions are as follows. The sample is maintained at $200^{\circ} \mathrm{C}$ between two $25 \mathrm{~mm}$ diameter parallel plates. The gap is fixed at $1 \mathrm{~mm}$. The analysis is performed with an oscillation frequency range between 0.001 and $50 \mathrm{~Hz}$, and a maximum applied amplitude of shear strain of $0.25 \%$.

The molecular weight $M_{w}$ influences the dynamic viscosity $\eta$ which is expressed by a scale law (Bueche's law) $)^{19}$ :

$\eta=K M_{w}^{\alpha}$

Where $\alpha$ is a universal constant: $\alpha=3.4 \pm 0,1$. The constant $K$ is determined from the initial value of the viscosity in the virgin state of PA11, knowing the initial value of the molecular mass $M_{w 0}$ :

$K=\frac{\eta_{0}}{M_{W 0}^{\alpha}}$

With $\mathrm{M}_{\mathrm{wo}}=100.4 \mathrm{~kg} \cdot \mathrm{mol}^{-1} . \mathrm{K}$ depends on the rigidity of the system and decreases with increasing temperature.

\section{Fourier Transform Infrared spectroscopy (FTIR)}

Samples were analyzed by IR spectrophotometry (Bruker IFS 28 spectrometer) between 600 and 4000 $\mathrm{cm}-1$ in transmission mode. The spectrum was an accumulation of 16 scans. The spectra are collected and analyzed on the Spectrum 10TM software (PerkinElmer). This technique makes possible to characterize the vibrational properties of the molecules and, in particular, the chemical bonds. It provides qualitative and quantitative information in terms of the composition of interatomic links. It was used in this paper to characterize the kinetics of chemical degradation by monitoring the absorption bands associated with the functional groups involved in the degradation.

\section{Dynamic Mechanical Thermal Analysis (DMTA)}

The dynamic mechanical properties were measured with a TA Q800 DMTA. Parallelepiped-shape samples with dimensions $40 \mathrm{~mm} \times 7.5 \mathrm{~mm} \times 1.5 \mathrm{~mm}$ were tested in a single cantilever beam arrangement. The tests were carried out with an imposed strain of $0.02 \%$ at a frequency of $1 \mathrm{~Hz}$. A temperature sweep from $-100{ }^{\circ} \mathrm{C}$ to $130{ }^{\circ} \mathrm{C}$ at a speed rate of $3{ }^{\circ} \mathrm{C} \cdot \mathrm{min}^{-1}$ was performed during the test. Storage ( $\left.E^{\prime}\right)$ and loss $\left(E^{\prime \prime}\right)$ modules, as well as $\tan \delta$ have been recorded. Two samples were analysed for each condition. The loss factor tan $\delta$ was calculated as a ratio between $E^{\prime}$ and $E^{\prime \prime}$ 


\section{Tensile test conditions}

Uniaxial tensile tests were carried out in an Instron ${ }^{\circledR}$ testing machine with a $5 \mathrm{kN}$ load cell. A traction speed of $5 \mathrm{~mm} \cdot \mathrm{min}^{-1}$ (i.e. $3.3 \times 10^{-3} \mathrm{~s}^{-1}$ ) was imposed by the crosshead at room temperature. The dimensions of tensile samples were taken according to the ASTM D638 standard. The results are presented in the form of curves connecting the nominal stress with the nominal axial strain. The nominal stress corresponds to the force given by the load sensor of the testing machine relative to the initial section of the sample. The nominal axial strain corresponds to the displacement of the crosshead divided by the reference length of sample (i.e. $40 \mathrm{~mm}$ ).

\section{RESULTS}

In this section, the results of physicochemical and mechanical characterizations are presented. Firstly, the aim was to identify physicochemical and mechanical descriptors of ageing ( $T, H+T$, etc. ...). Then, links between the evolution of the microstructural descriptors and the evolution of the mechanical descriptors are presented.

\section{Crystallinity Measurement by DSC}

Since the degree of crystallinity $\left(X_{c}\right)$ evolved with temperature, time and chemical modifications, several tests were performed to separate the different effects. Figure 2 shows the set of thermograms obtained for each ageing condition. By calculating the area under the heating curve, and normalizing it by the melting enthalpy value of a $100 \%$ crystalline PA11 $\left(\Delta H_{m}^{0}\right)$, the crystallinity rate of our sample was obtained by classical relation:

$X c_{D S C}=100 * \frac{\Delta H_{m}}{\Delta H_{m}^{0}}$

with $\Delta \mathrm{H}_{\mathrm{m}}$ the melting enthalpy of the material determined by the area of the melting peak, $\Delta \mathrm{H}_{\mathrm{m}}{ }^{0}$ the enthalpy of the fusion of the purely crystalline polymer $\left(226.4 \mathrm{J.g}^{-1}\right.$ for PA11) ${ }^{20}$.

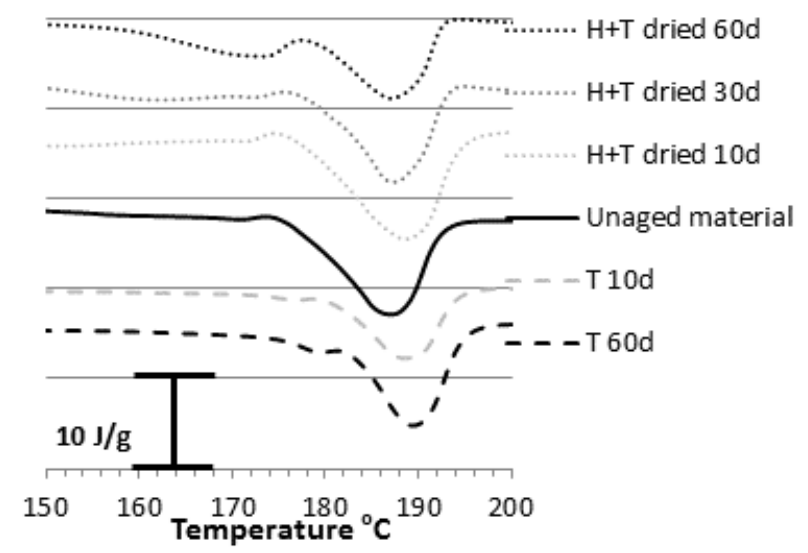

Figure 2 DSC Thermograms during the heating of PA11 aged in temperature (T) and aged in hydrolysis (H+T).

The degree of crystallinity increases during ageing from $18 \%$ to $30 \%$ after 60 days of ageing at pH 4 / $110{ }^{\circ} \mathrm{C}$. DSC crystallinity analysis (Figure 3 ) does not provide sufficient fine elements to assert that a part 
of crystallinity increase was due to chemical crystallization. The crystallinity of the thermal control material evolves in the same order. A more detailed observation of the thermograms reveals a main melting peak at $\sim 186^{\circ} \mathrm{C}$, corresponding to the crystal phase $\alpha$ of PA11, and the emergence of a more diffuse melting halo at a lower temperature for both configurations of ageing. This halo reflects the presence of a second crystal phase, less organized than the crystal population of the main peak. However, in the case of thermal ageing "T", this second peak was less diffuse around $178^{\circ} \mathrm{C}$. It was the signature of a metastable phase, pseudo-hexagonal smectic $\delta$ '. ${ }^{21,22}$

The dried aged samples have a very slightly higher level. If there was chemo-crystallization, it seems that it was of second order compared to the thermal effect, or it generates a similar structure from the energy point of view than the thermal control.



Figure 3 Total mass enthalpy for thermal (T) and thermal and hydrolyzed ageing $(\mathrm{H}+\mathrm{T})$

At first heating, the main melting peak changes shortly after ageing $\mathrm{T}$ or $\mathrm{H}+\mathrm{T}\left(188^{\circ} \mathrm{C}\right)$. A secondary crystalline family develops and results in a second peak at $172^{\circ} \mathrm{C}$ (Figure 2) during both protocols. This second population was assumed to be a consequence of chain cuts. Free radicals would be created during the extrusion of the tapes, as was known that the presence of peroxide radicals can induce degradation of the materials by chain cuts $^{23-26}$. Consequently chain cuts would evolve during both thermal ageing. In order to quantify the recrystallization, a dissociation of the melting peaks was made according to Figure 4. The initial family is called the crystalline structure corresponding to the main fusion peak and the secondary family is called the crystalline structure corresponding to the fusion halo. 
These cut chains would enhance a secondary family of crystals which increases during the time, to the detriment of the initial family (Figure 5). However, it was difficult to know precisely where chain cuts occur at this stage of the study.



Figure 5 Enthalpy of fusion of the two crystalline families with time and type of ageing $(T)$ and $(H+T)$

$$
\begin{aligned}
& \text { In broken lines: Initial family } \\
& \text { Dotted line: Secondary family }
\end{aligned}
$$

In continuous lines: Sum of the two families

\section{GPC \& rheological measurement and molecular weight calculation}

The influence of each ageing ( $\mathrm{T}$ and $\mathrm{H}+\mathrm{T}$ ) on the length of the macromolecular chains was analyzed, in particular on the molecular weight in number $(\mathrm{Mn})$ and weight $(\mathrm{Mw})$. The evolution of molecular weight as a function of the duration of each ageing process was shown Figure 6. It appears that kinetics was similar to those identified from the DSC tests. 


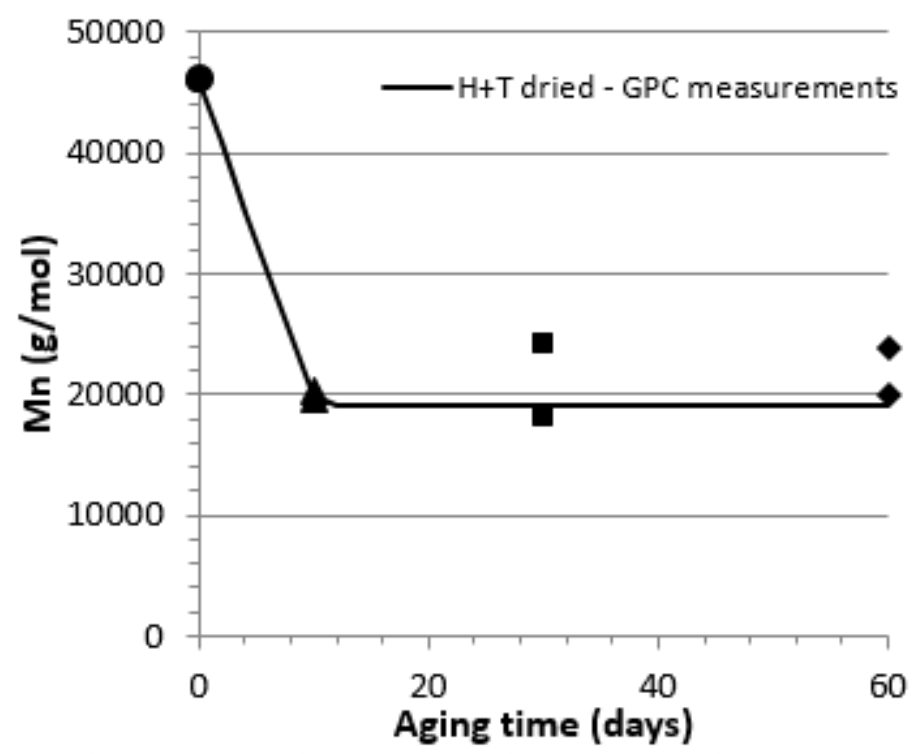

Figure 6 Molecular weights for dried $\mathrm{H}+\mathrm{T}$ samples as a function of ageing time

On $\mathrm{H}+\mathrm{T}$ aged samples, the molecular weight was halved after 10 days of ageing, and then stabilizes at around 20000 g.mol${ }^{-1}$. CES measurements confirm a deterioration by chain breaks. Compared to the literature, the degradation observed here very rapid. ${ }^{27}$ Merdas et al. show that the molecular weight was halved after about 15 days at $\mathrm{pH} 4$ and $130^{\circ} \mathrm{C}$. A superposition of another chain break phenomenon can be envisaged. Few variations are observed on the polydispersity index, which was a marker for the homogeneity of the hydrolysis process within the material.

Data obtained from rheological measurements are presented in Figure 7 in terms of dynamic viscosity $\eta$. The viscosity of the molten polymer becomes constant at low shear rates. The viscosity in this region was called Newtonian viscosity $\left(\eta_{0}\right)$. Dynamic viscosity decreases with ageing. Moreover, we observed that the width of the Newtonian plateau increases when the molecular mass decreases.

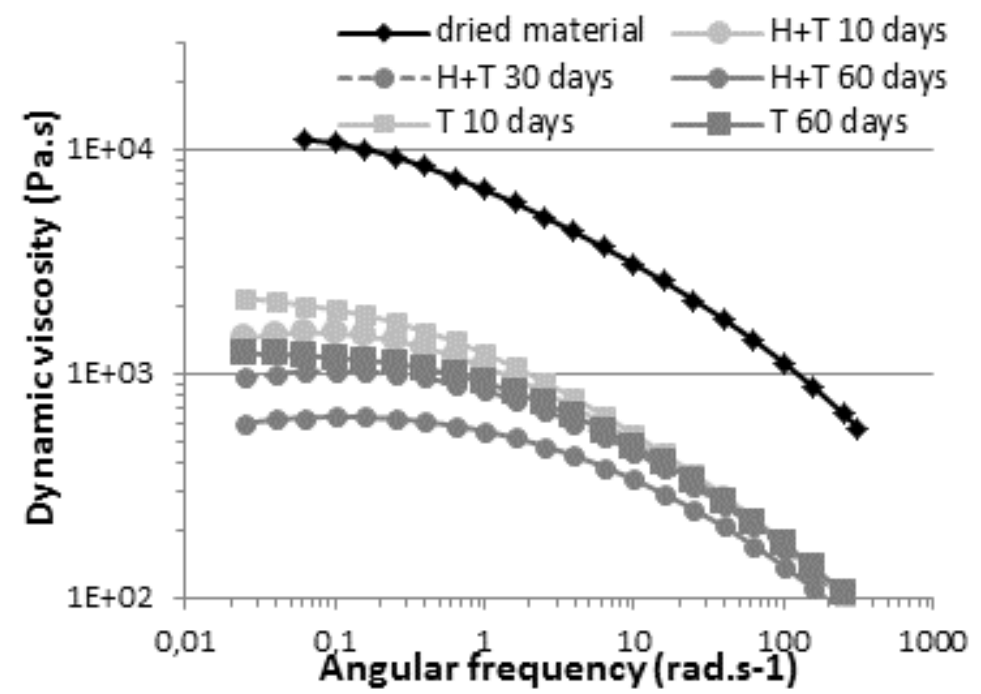

Figure 7 Evolution of dynamic viscosity with ageing time and type $(\mathrm{T})$ and $(\mathrm{H}+\mathrm{T})$ 
It was noted that the molecular weight of the sample subjected to ageing $(T)$ decreases compared to the control sample (Figure 8) in the same characteristic time. This confirms the consequence of the oxidation degradation due to the free radicals created in the material during extrusion. In samples aged at $\mathrm{pH} 4 / 110^{\circ} \mathrm{C}$, the molecular weight was divided by 2 after 60 days. The hydrolysis results in the drop of the molecular mass, the rheological measurements confirm a degradation by chain cuts. During ageing $(\mathrm{H}+\mathrm{T})$, chain breaks by hydrolysis are added to chain cuts due to the peroxides created during the extrusion. Therefore, the molecular mass for ageing $(H+T)$ was even lower than for ageing $(T)$.

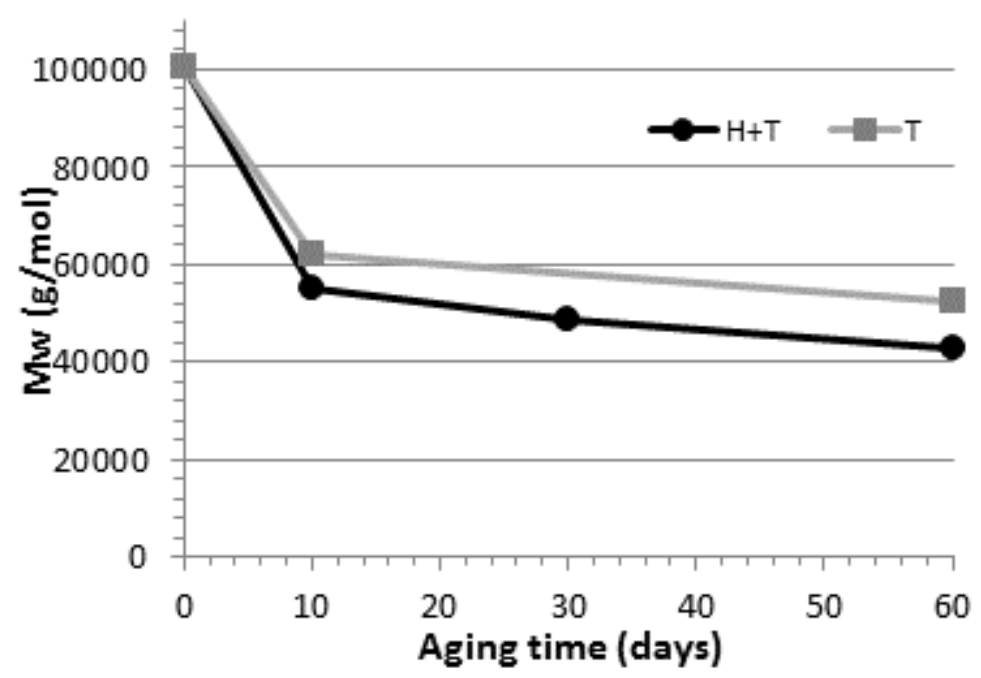

Figure 8 Decrease in molecular weight with ageing $(T)$ and $(H+T)$

Figure 9 compares the molecular masses obtained by GPC and by viscosity measurement and demonstrates the consistency of the two bodies of results.

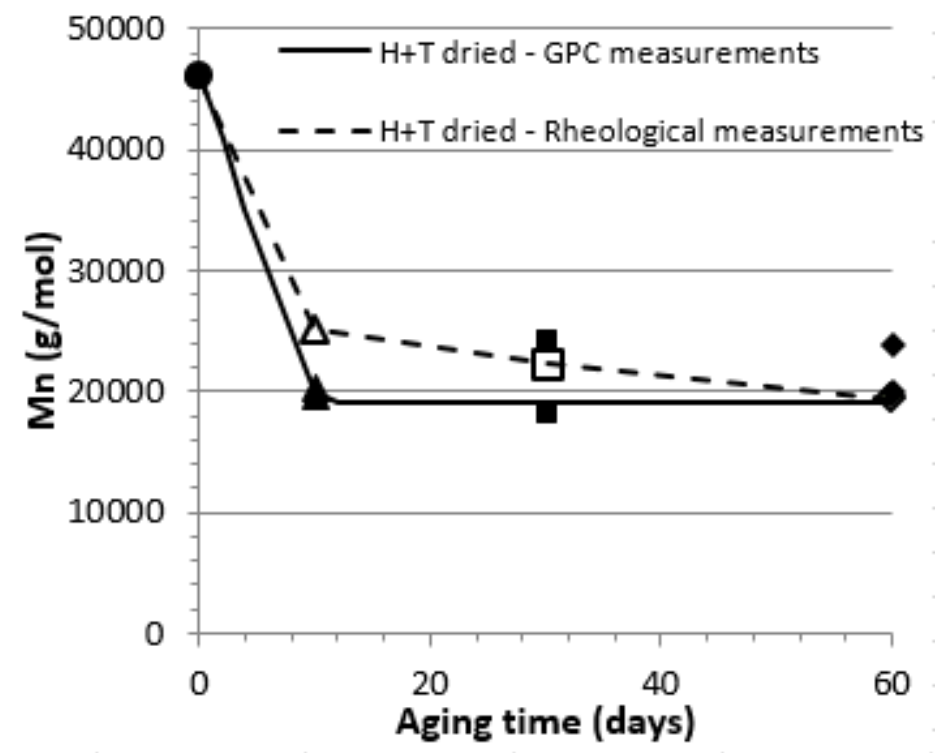

Figure 9 Comparison of the two molecular weight techniques for dry $\mathrm{H}+\mathrm{T}$ samples

\section{Modification of chemical functions}


FTIR was used to locate the chain cuts and confirm the presence of oxidation in thermally aged material (T) and/or $\mathrm{H}+\mathrm{T}$ material.

The spectrum corresponding to the as received PA11 was shown in Figure 10. It was conform to the literature ${ }^{4,28,29}$. Each absorption peak corresponds to a molecular bond. The allocation of the FTIR bands of PA11 was presented in Table 3. These molecular bonds can be impacted by ageing. The area between 1900 and $1500 \mathrm{~cm}^{-1}$ and the area between 750 and $650 \mathrm{~cm}^{-1}$ in the dashed frames on Figure 10 were studied to characterize ageing in our study conditions.

An increase in the absorption signal between 1700 and $1790 \mathrm{~cm}^{-1}$ was observed for thermal (T) and thermohydric $(\mathrm{H}+\mathrm{T})$ ageing (Figure 11). The control material also appears to have an increase in absorbance around $1740 \mathrm{~cm}^{-1}$. This was attributed to the presence of hydroperoxides in the material and confirms the previous results. During extrusion, PA11 was heated extensively; andthese high temperatures in air can cause oxidation of PA11 with the decomposition of hydroperoxides ${ }^{25}$. But these short chains were supposed to do not react chemically with the environment at room temperature.

However, during thermal or thermohydric ageing, an increase in the absorption peak associated with the imide function in agreement with the presence of oxidation ${ }^{30,31}$. It was found that the ageing protocol set up in a neutral environment $(T)$ is not eliminate an oxidation phenomenon despite the taken precautions.

\begin{tabular}{|c|c|}
\hline Frequency $\left(\mathrm{cm}^{-1}\right)$ & Assignment \\
\hline 3302 & $\mathrm{NH}$ bond \\
\hline 3082 & Resonance of Fermi ( $\delta \mathrm{NH}$ amide II) \\
\hline 2918 & Asymmetric stretch $\mathrm{CH}_{2}$ \\
\hline 2848 & Symmetric stretch $\mathrm{CH}_{2}$ \\
\hline $1756 \& 1711$ & Carboxylic acids (isolated and bound) \\
\hline 1734 & Imide \\
\hline 1634 & Amide I stretch $(C=O)$ \\
\hline 1541 & Amide II groups - $\mathrm{NH}-\mathrm{CO}-$ \\
\hline 1161 & Interaction between stretch \& deformation $(\mathrm{O}=\mathrm{C}-\mathrm{N})$ \\
\hline 937 & Amide IV $\delta \mathrm{CONH}$ \\
\hline 720 & Oscillation $\mathrm{CH}_{2}$ \\
\hline 688 & Crystalline phase (triclinic) \\
\hline 580 & Crystalline phase (triclinic) \\
\hline
\end{tabular}




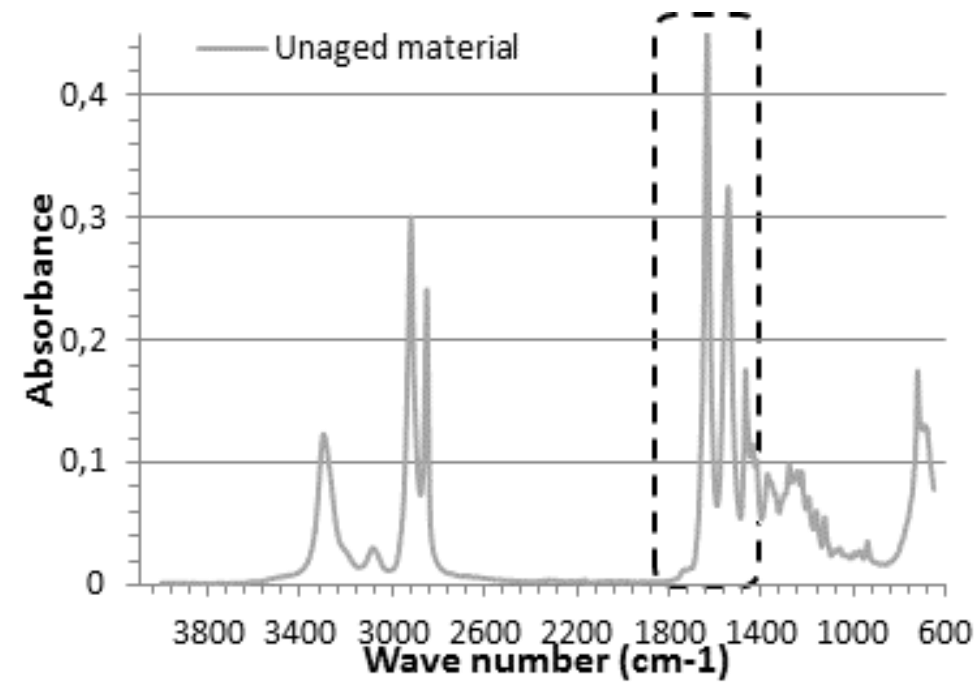

Figure 10 IRTF spectrum of healthy PA11.

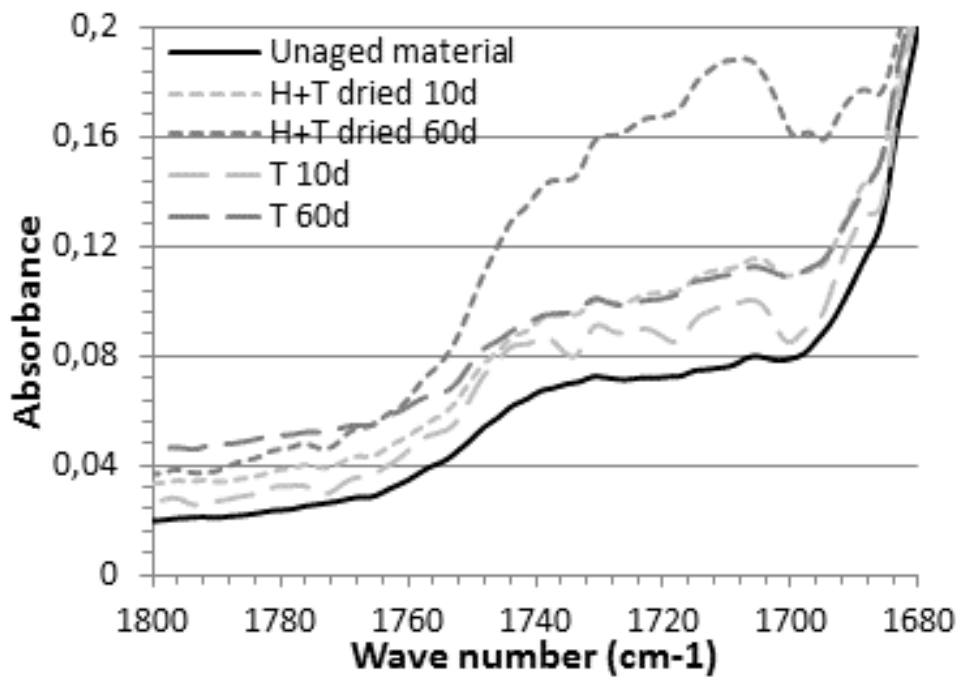

Figure 11 Evolutions of the absorbance of the IR peak attributed to carbonyls

Another absorption peak was visible around $1710 \mathrm{~cm}^{-1}$. This peak corresponds to the presence of the carboxylic acid function. It was hardly visible in the case of a as received material, and appears during ( $T$ ) and $(\mathrm{H}+\mathrm{T})$ ageing. The presence of the carboxylic acid function was very important in the case of $\mathrm{H}+\mathrm{T}$ ageing at 60 days. During $\mathrm{H}+\mathrm{T}$ ageing, the carboxylic acid can be attributed mainly to hydrolysis. In the case of ageing $\mathrm{T}$, the absorbance associated with the acid was much less. Compared with the literature ${ }^{30}$, the absorbance attributed to the isolated carboxylic acids $\left(1756 \mathrm{~cm}^{-1}\right)$ was low and does not allow to characterize this chemical species in our case.

\section{DMTA}

Figure 12 and Figure 13 show the storage modulus and damping factor ( $\tan \delta$ ) of samples at different stages of degradation, as a function of temperature. Alpha relaxation involves hydrogen bonded amide groups. ${ }^{32}$ It was associated with the glass transition $(\mathrm{Tg})$ of the material. The shift of the peak reveals a significant increase in $\mathrm{Tg}$ for $\mathrm{H}+\mathrm{T}$ ageing and nearly no evolution for $\mathrm{T}$ ageing. 
Figure 12 shows that the stiffness increases with ageing time, from 10 days of $(T)$ and $(H+T)$ ageing. The stiffness increases for ageing $(T)$ and more importantly for an ageing $(H+T)$. In principle, the phenomenon of thermal annealing increases the crystallinity, which was consistent with an increase in the rigidity of the material.

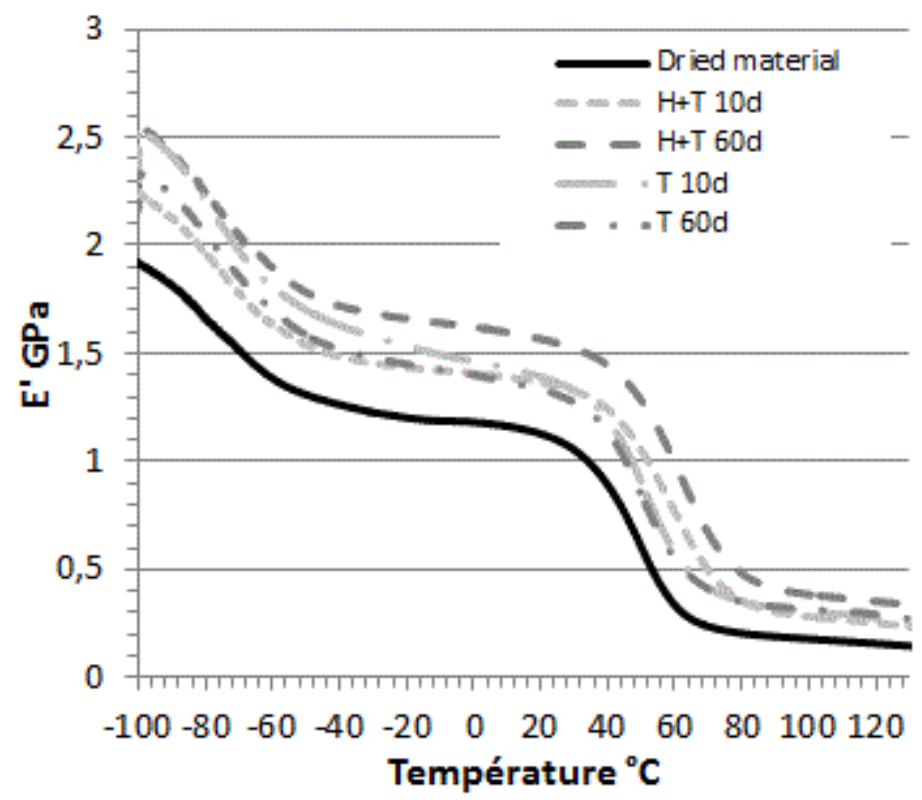

Figure 12 Storage modulus of PA11 before and after ageing $(\mathrm{T})$ at $110^{\circ} \mathrm{C}$ and $(\mathrm{H}+\mathrm{T})$ at $\mathrm{pH} 4 / 110^{\circ} \mathrm{C}$

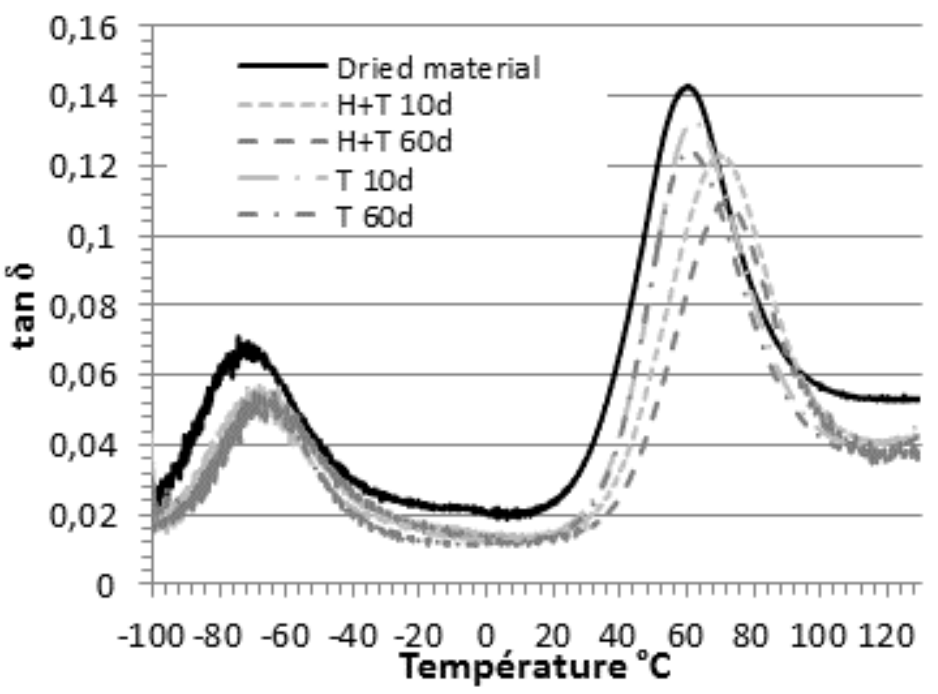

Figure 13 Evolution of tan $\delta$ before and after ageing $(\mathrm{T})$ at $110^{\circ} \mathrm{C}$ and $(\mathrm{H}+\mathrm{T})$ at $\mathrm{pH} 4 / 110^{\circ} \mathrm{C}$

The $\mathrm{Tg}$ decrease observed during ageing $\mathrm{H}+\mathrm{T}$ in samples saturated with water (Figure 14), was assumed to result from the plasticization by water of the material, which promotes the mobility of the macromolecular chains ${ }^{33,34}$. The impact of hydrolysis was less important than the plasticizing effect of water in this case. $\mathrm{Tg}$ of the dry $\mathrm{H}+\mathrm{T}$ samples increases with ageing time. It was related to the significant recrystallization of the samples. In the case of purely thermal ageing, the stiffness was impacted 
(relatively to the control material), but the $\mathrm{Tg}$ was quasi-constant, which suggests that the mobility of the amorphous phase was not impacted.

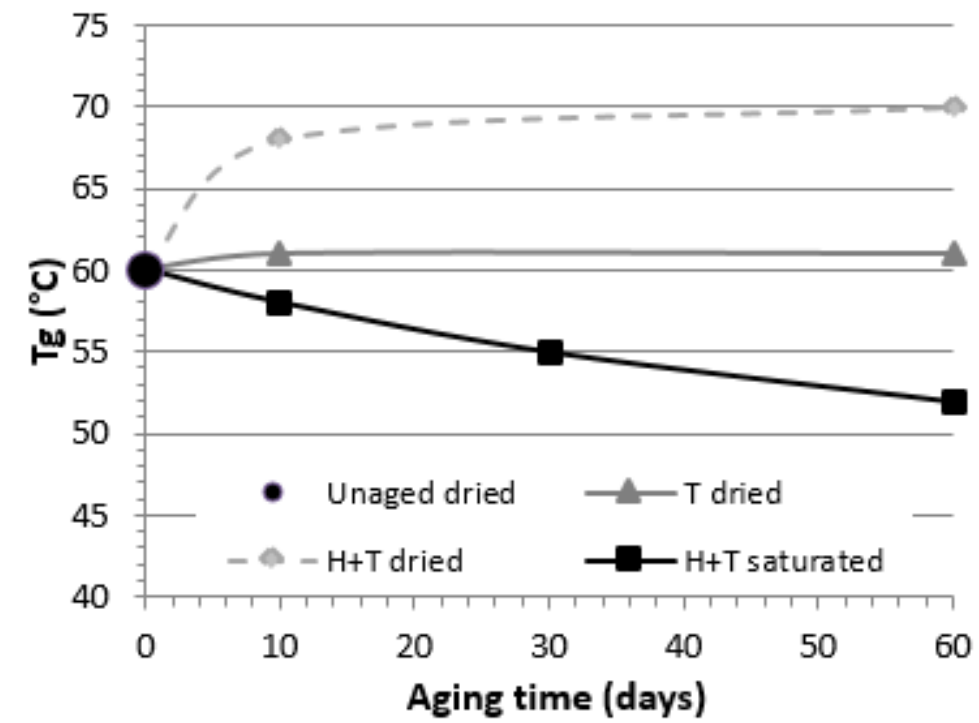

Figure 14 Evolution of $\mathrm{Tg}$ with ageing time for unaged dried, $\mathrm{T}, \mathrm{H}+\mathrm{T}$ dried, $\mathrm{H}+\mathrm{T}$ satured ageing

The changes observed during chemical physico characterizations were confronted with changes in mechanical behaviour in order to find links between the different descriptors.

\section{Tensile test}

\section{Unaged and dried sample}

At $20{ }^{\circ} \mathrm{C}$, an elastic slope is observed, followed by a first yield at $7 \%$ of strain and then a second yield (Figure 15 Mechanical behavior of non-aged PA11 during uniaxial tensile stress at $20^{\circ} \mathrm{C}$ ). According to Belec, ${ }^{15}$ the first yield stress corresponds to a plasticization of the crystals, and the second one to a breakage of crystals. Moreover, a whitening of the material appears was between the first and second yields, indicating a damage by cavitation (Figure 16). ${ }^{35-37}$ Points 1 to 5 in Figure 15 correspond to the pictures of the samples in Figure 16. Point 1 corresponds to the start of the test and point 2 corresponds to the 1st yield, showing no whitening. Point 3, which corresponds to a strain of approximately $15 \%$, shows signs of whitening over the full reference zone (gauge length). Point 4 corresponds to the 2 nd yield and shows a more pronounced whitening. Finally, at the beginning of the neck corresponding to a strain of about $40 \%$, whitening was important throughout the specimen and even more in the neck (point 5). 


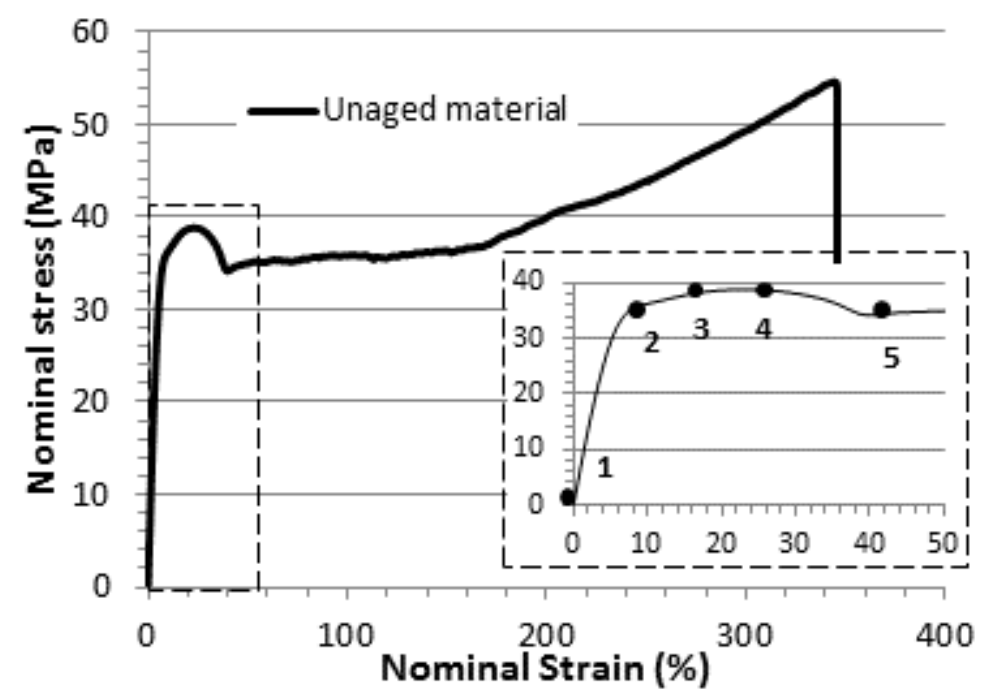

Figure 15 Mechanical behavior of non-aged PA11 during uniaxial tensile stress at $20^{\circ} \mathrm{C}$
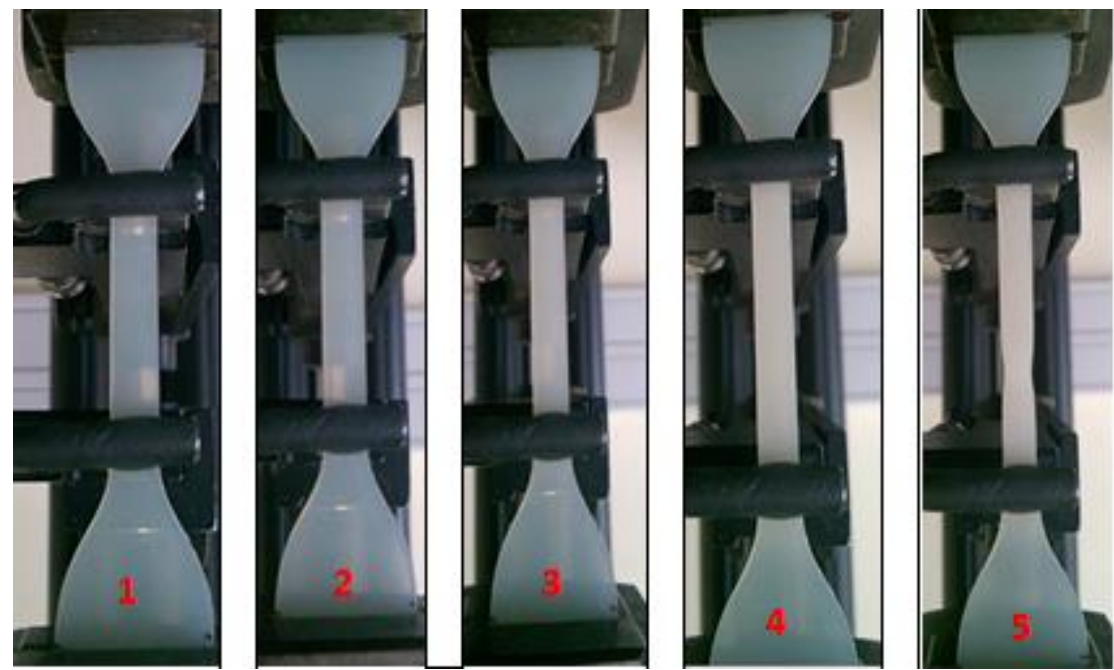

Figure 16 Evolution of specimen whitening to $0 \%(1), 7 \%(2), 15 \%(3), 26 \%(4)$ and $42 \%(5)$ strain of unaged PA11

\section{$T$ samples and $H+T$ samples}

The evolution of the tensile behavior was shown on Figure 17 and Figure 18 for the dried test pieces after ageing $\mathrm{T}$ and $\mathrm{H}+\mathrm{T}$. R are presented in nominal stress, i.e. the force relative to the initial section of the specimens. It must be underlined that all specimens are dried before testing in order to avoid the plasticizing effect of water. 




Figure 17 Stress-strain curves at $20^{\circ} \mathrm{C}$ for PA11 aged in temperature (T) at $110^{\circ} \mathrm{C}$ and aged in water, temperature and dried $(\mathrm{H}+\mathrm{T})$ at $\mathrm{pH} 4 / 110^{\circ} \mathrm{C}$

From 10 days of ageing $\mathrm{H}+\mathrm{T}$, a drop in the strain at break was observed, due to hydrolysis and free radicals action. The unaged material has a strain at break of $320 \%$. This value drops to about $60 \%$ after 10 days of $\mathrm{H}+\mathrm{T}$ ageing. It was only about $18 \%$ after 60 days of $\mathrm{H}+\mathrm{T}$ ageing. For thermal ageing (T), the decrease of the strain at break was less important because it only depends on the presence of free radicals created during the extrusion of the tapes. There was also a significant increase in stress at the second yield between the virgin state and the aged states $(T)$ and $(H+T)$. This was due to the thermal annealing phenomenon linked to secondary crystallization. ${ }^{16,17,38}$ In addition, the double "yield" seems to be accentuated after annealing.



Figure 18 Stress-strain curves at $20^{\circ} \mathrm{C}$ for moderate deformations for PA11 aged in temperature (T) at $110^{\circ} \mathrm{C}$ and aged in water, temperature and dried $(\mathrm{H}+\mathrm{T})$ at $\mathrm{pH} 4 / 110^{\circ} \mathrm{C}$

Figure 18 shows an increase in Young's modulus and second yield with ageing. Between 30 days and 60 days, other mechanisms seem to have taken place in the crystal lattice to visualize such a large increase 
in the first yield. This was due to a higher degree of crystallinity. The larger crystalline phase requires more energy to reach the second yield. ${ }^{17}$

\section{DISCUSSION}

\section{Relationship between microstructure and mechanical properties}

\section{Strain at break - Molecular weight}

During ageing, the strain at break decreases. It was one of the markers of material embrittlement. As the molecular weight falls as a result of chain cuts, it was often linked to the strain at break. ${ }^{14,7}$ In the case of amorphous polymers, if the molar mass was below a critical molar mass $\mathrm{M}^{\prime}{ }_{\mathrm{c}}$, the polymer was brittle. This molar mass was related to the presence of mechanically active entanglements. The case of semi-crystalline polymers was more complex because the ductile-brittle transition was closely related to the semi-crystalline microstructure. However, the molar mass vs. strain at break relationship can be a first approach to connect physico-chemistry to mechanics (Figure 19). Here, both hydrolysis and free radicals are responsible for chains cuts leading to the reduction of the strain at break.

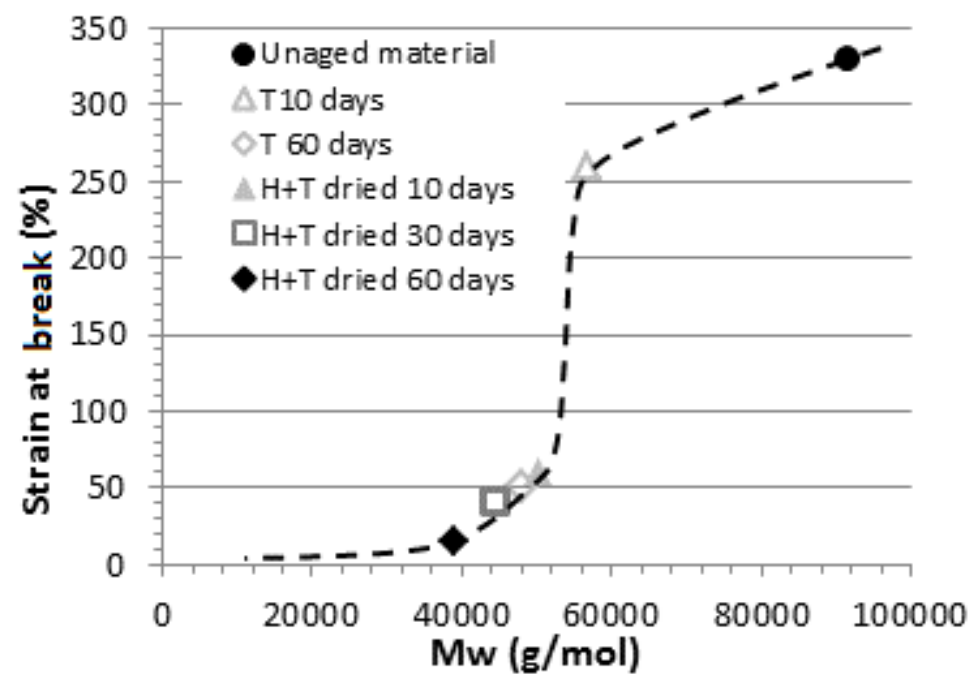

Figure 19 Strain at break as a function of weight average molar mass obtained after $\mathrm{T}$ ageing $\left(110^{\circ} \mathrm{C}\right)$ and $\mathrm{H}+\mathrm{T}$ ageing $\left(\mathrm{pH} 4 / 110^{\circ} \mathrm{C}\right)$.

\section{2nd yield Stress - Crystallinity rate}

Recrystallization was attributed to two phenomena that can be coupled:

- An increase in temperature leading to increased chain mobility and possible recrystallization (thermal annealing).

- Chain breaks that can release short, mobile segments that can enrich the crystalline phase already present (chemo-crystallization)

The evolution of the 2 nd yield in stress with ageing $\mathrm{T}$ and $\mathrm{H}+\mathrm{T}$ was reminded on Figure 20, based on tensile-to-failure tests. It should be noted that recrystallization has no significant effect on the first yield. 
Indeed, the evolution of the mechanical behavior up to the first yield was related to the sliding of the chains in the amorphous phase ${ }^{15}$.

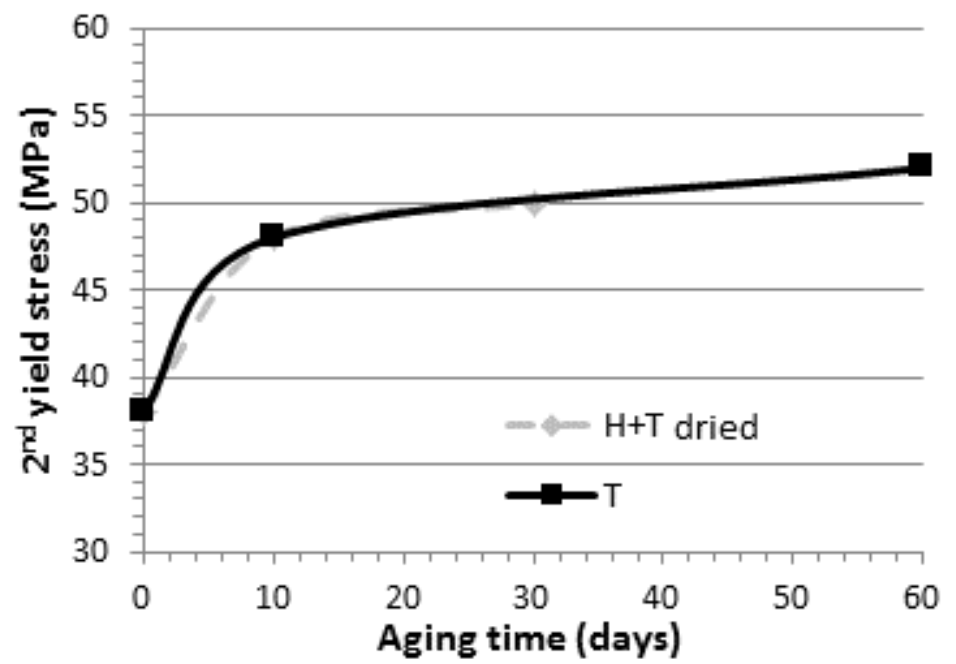

Figure 20 Evolutions of the crystallinity and the yield stress in the case of thermal ageing $(\mathrm{T})$ and water ageing $(\mathrm{H}+\mathrm{T})$

A relationship was appeared when the crystallinity rate was compared with the evolution of the stress at the 2nd plasticity yield (Figure 21). This analysis was relevant because annealing due to temperature will thicken the crystallites. Moreover, the 2 nd yield disappears above the Tg; it suggests that this behavior was essentially related to the deformation of the amorphous phase ${ }^{15}$. These deformations in the amorphous phase result in micro shear bands that will be blocked by the crystals, which leads to the stage of tensile consolidation and the increase in stress between the 1 st and 2 nd yields ${ }^{15}$. It seems consistent to think that the more crystallinity was important, the more shears micro-bands in the amorphous phase will be blocked; which results in a significant increase in the 2 nd yield. The two developments can therefore be linked.

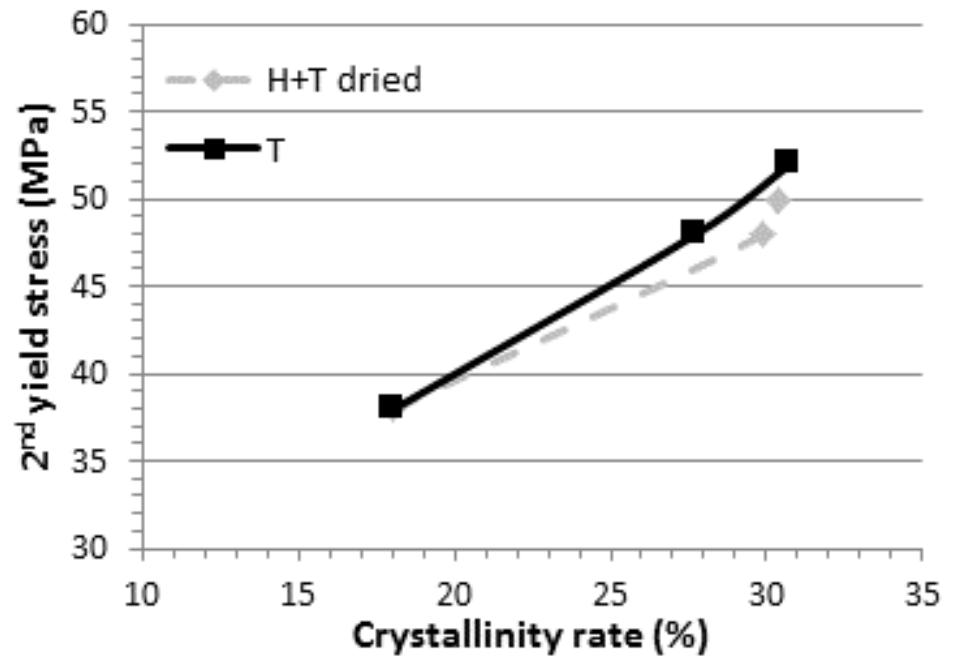

Figure 21 Relation between the 2 nd yield stress with crystallinity for T ageing and H+T ageing

\section{CONCLUSIONS}


The ageing in water and in temperature of a polyamide 11 (PA11) has been investigated. Physicochemical and chemical descriptors were studied, in order to establish a link between microstructure and macroscopic properties. The superposition of the different evolutions of the microstructure during ageing leads us to carry out different ageing processes in order to decouple the phenomena.

PA11 absorbs about $1.8 \%$ of water, confirming that PA11 is rather hydrophilic. In this work, the recovery in water after the fickien plateau is not present. The diffuse reactive model without water trapping provides us with the equilibrium content ( 1.8\%), but poorly reproduces the water loss after 10 days of ageing. The water recovery depends on the ageing protocol which can influence the results.

The monitoring of the crystallinity rate showed a recrystallisation of the material in the case of thermohydraulic ageing as well as in the case of purely thermal ageing. Recrystallization is observed after 10 days and then stabilizes up to 60 days of ageing. A second peak at the foot of the main melting peak was observed on the DSC thermograms. This rather ordered peak in the case of purely thermal ageing corresponds to the crystalline phase $\delta$ which forms during thermal annealing. In the case of thermohydric ageing, this second peak is less well organised, the chain cuts linked to hydrolysis undoubtedly disturbing this second crystalline phase. The FTIR also showed partial results on recrystallization because we did not have access to absorption peaks for small numbers of waves (below $650 \mathrm{~cm}-1)$. Nevertheless, the only absorption peak corresponding to the crystalline phase showed a greater recrystallization in the case of $\mathrm{H}+\mathrm{T}$ ageing than in the case of $\mathrm{T}$ ageing.

Molecular mass decreases significantly during ageing. This drop is the signature of a chemical degradation attributed in one case to oxidation $(T)$ and in the other to a superposition of oxidation and hydrolysis $(\mathrm{H}+\mathrm{T})$. This size thus makes it possible to determine the number of chain cuts within the material. The FTIR confirmed that the chain cuts in the thermally aged material are due to the presence of oxidation.

$\mathrm{Tg}$ decreases significantly during thermohydric ageing with the presence of water. Indeed, the plasticizing role of water reduces interactions between molecular chains. When the influence of water is removed (drying), Tg increases for both types of ageing, but more for $\mathrm{H}+\mathrm{T}$ ageing. In the latter case, this is due to the significant recrystallization and in particular to the appearance and development of the secondary crystal family observed by DSC.

A mechanical test campaign was carried out to determine the impact of ageing on the viscoplastic macroscopic behaviour characteristic of PA11 in its virgin and aged state, attempting to dissociate the effects of physical ageing from those purely related to hydrolysis. The following points should be noted: The evolution of the mechanical behaviour during $\mathrm{T}$ ageing and $\mathrm{H}+\mathrm{T}$ ageing results in a significant drop in the deformation at break as well as an increase in the Young's modulus and an increase in the stress at the 2 nd yield. The second yield is marked significantly and is attributed to recrystallization. The first stress yield is only affected for long times in both ageing configurations. The bleaching of the working area of the tension specimens shows the initiation of cavitation damage in the material between the 1st and 2 nd yield for healthy and aged material. 
The reduction in deformation at break is much more marked in the case of thermohydrolytic ageing than in the case of thermal ageing. Moreover, the decrease in deformation at break in the case of thermal ageing is due to the presence of oxidation.

The signature of hydrolytic ageing was clear on the mechanical behaviour, at least in uniaxial traction. Indeed, the ductile behaviour of healthy PA11 with cavitation damage gives way to a fragile behaviour following chain cutting mechanisms by hydrolysis and/or oxidation. In the aged state, characterisation of the damage was more difficult. Damage mechanisms were likely to occur on a scale that is difficult to access using standard characterization techniques. It would be interesting to try to characterize these damage mechanisms by in situ measurements (SAXS, microtomography, etc...).

The next step was to integrate the different relationship in a mechanical model of semi-crystalline polymers. The variability of the mechanical behavior was captured by model parameters, more or less explicitly linked to the microstructural state of the material. In the case of wet ageing, it will be necessary to change its mechanical parameters with the degree of ageing through descriptors identified in this article. The modelling work will be detailed in a separate article.

\section{ACKNOWLEDGEMENTS}

The authors would like to express their gratitude to ENSAM and the PIMM laboratory for technical support. Thanks are also extended to Bruno Fayolle for our productive scientific discussions.

\section{REFERENCES AND NOTES}

1. Boubakri, a., Haddar, N., Elleuch, K. \& Bienvenu, Y. Influence of thermal ageing on tensile and creep behavior of thermoplastic polyurethane. Comptes Rendus Mécanique 339, 666-673 (2011).

2. Terselius, D. F. B. Thermo oxidative stability of polyamide 6 films I. Mechanical and chemical characterisation. Polym. Degrad. Stab. 67, 69-78 (2000).

3. Mazan, T., Berggren, R., Jørgensen, J. K. \& Echtermeyer, A. Ageing of polyamide 11. Part 1: Evaluating degradation by thermal, mechanical, and viscometric analysis. J. Appl. Polym. Sci. 132, 1-11 (2015).

4. Domingos, E., Pereira, T. M. C., Castro, E. V. R. De, Romão, W. \& Sena, G. L. De. Monitorando a Degradação da Poliamida 11 ( PA-11 ) via Espectroscopia na região do Infravermelho médio com Transformada de Fourier. Polímeros 23, 37-41 (2013).

5. Broudin, M. et al. Water diffusivity in PA66 : Experimental characterization and modeling based on free volume theory. Eur. Polym. J. 67, 326-334 (2015).

6. Hocker, S., Rhudy, A. K., Ginsburg, G. \& Kranbuehl, D. E. Polyamide hydrolysis accelerated by small weak organic acids. Polym. (United Kingdom) 55, 5057-5064 (2014).

7. El-Mazry, C., Ben Hassine, M., Correc, O. \& Colin, X. Thermal oxidation kinetics of additive free polyamide 6-6. Polym. Degrad. Stab. 98, 22-36 (2013).

8. Angewandte, D. \& Chemie, M. I+. 110, 71-85 (1989). 
9. Redhead, A. \& Frank, A. Implementation of a new chlorine dioxide device for accelerated ageing of polyolefin pipe materials. in 18th Plastic Pipes Conference (2016).

doi:10.13140/RG.2.2.24112.35846

10. Habas-ulloa, A. et al. Creep Behavior of High Density Polyethylene after Ageing in Contact with Different Oil Derivates. (2010). doi:10.1002/pen

11. El-Mazry, C., Correc, O. \& Colin, X. A new kinetic model for predicting polyamide 6-6 hydrolysis and its mechanical embrittlement. Polym. Degrad. Stab. 97, 1049-1059 (2012).

12. Jacques, B., Werth, M., Merdas, I., Thominette, F. \& Verdu, J. Hydrolytic ageing of polyamide 11. 1. Hydrolysis kinetics in water. Polymer (Guildf). 43, 6439-6447 (2002).

13. Serpe, G., Chaupart, N. \& Verdu\{, J. Ageing of polyamide 11 in acid solutions. Polymer (Guildf). 38, 1911-1917 (1997).

14. Fayolle, B., Colin, X., Audouin, L. \& Verdu, J. Mechanism of degradation induced embrittlement in polyethylene. Polym. Degrad. Stab. 92, 231-238 (2007).

15. L.Bélec. Mise en évidence de la contribution des phases amorphe et cristallines dans la déformation du polyamide 11 et du polyamide 12 autour de la transition vitreuse. (Université de Poitiers, 1995).

16. Brooks, N. W., Duckett, R. A. \& Ward, I. M. Investigation into double yield points in polyethylene. Polymer (Guildf). 33, 1872-1880 (1992).

17. Séguéla, R. \& Darras, O. Phenomenological aspects of the double yield of polyethylene and related copolymers under tensile loading. J. Mater. Sci. 29, 5342-5352 (1994).

18. Puffr, R., Bebenda, J., Šebenda, J., Bebenda, J. \& Šebenda, J. On the Structure and Properties of Polyamides. XXVII. The Mechanism of Water Sorption in Polyamides. J. Polym. Sci. Part C Polym. Symp. 16, 79-93 (2007).

19. Bueche F. Physical properties of polymers. (1962).

20. Inoue, M. \& Company, T. R. Studies on Crystallization of High Polymers by Differential Thermal Analysis. J. Polym. Sci. part A 1, 2697-2709 (1963).

21. Autran, J.-P. Structure, deformation behavior and properties in polyundecanamide (nylon 11 ) and high density polyethylene ( HDPE ) subjected to planar ( equibiaxial ) deformation by forging /. (University of Massachusetts, 1990).

22. Chocinski-Arnault, L., Gaudefroy, V., Gacougnolle, J. L. \& Rivière, A. Memory Effect and Crystalline Structure in Polyamide 11. J. Macromol. Sci. Part B 41, 777-785 (2002).

23. Machado, A. V, Covas, J. A. \& Duin, M. V. A. N. Monitoring Polyolefin Modification Along the Axis of a Twin Screw Extruder . I . Effect of Peroxide Concentration. J. Appl. Polym. Sci. 81, 58-68 (2001).

24. Azizi, H. \& Ghasemi, I. Reactive extrusion of polypropylene : production of controlled-rheology polypropylene ( CRPP ) by peroxide- promoted degradation. Polym. Test. 23, 137-143 (2004). 
25. Berzin, F., Vergnes, B., Canevarolo, S. V, Machado, A. V \& Covas, J. A. Evolution of the PeroxideInduced Degradation of Polypropylene Along a Twin-Screw Extruder : Experimental Data and Theoretical Predictions. J. Appl. Polym. Sci. 99, 2082-2090 (2005).

26. Caulfield, M. J., Qiao, G. G. \& Solomon, D. H. Some Aspects of the Properties and Degradation of Polyacrylamides. Chem. Rev. 102, 3067-3084 (2002).

27. Merdas, I., Thominette, F. \& Verdu, J. Hydrolytic ageing of polyamide 11 - effect of carbon dioxide on polyamide 11 hydrolysis. Polym. Degrad. Stab. 79, 419-425 (2002).

28. Chaupart, N. Vieillissement hydrolytique du polyamide 11. (PARIs VI, 1995).

29. Mécanique, S. Docteur I' École Nationale Supérieure d â€ $€^{\mathrm{TM}}$ Arts et Métiers. (2006).

30. Okamba-Diogo, O. et al. Molecular and macromolecular structure changes in polyamide 11 during thermal oxidation. Polym. Degrad. Stab. 108, 123-132 (2014).

31. Lemaire, J., Gardette, J., Rivaton, A. \& Roger, A. Dual Photo-chemistries in Aliphatic Polyamides, Bisphenol A Polycarbonate and Aromatic Polyurethanes-A Short Review. Polym. Degrad. Stab. 15, 1-13 (1986).

32. Kawaguchi, T. The Dynamic Mechanical Properties. J. Appl. Polym. Sci. 1, 56-61 (1959).

33. Miri, V., Persyn, O., Lefebvre, J.-M. \& Seguela, R. Effect of water absorption on the plastic deformation behavior of nylon 6. Eur. Polym. J. 45, 757-762 (2009).

34. Kettle, G. J. Variation of the glass transition temperature of nylon-6 with changing water content. Polymer (Guildf). 18, 742-743 (1977).

35. Boisot, G., Laiarinandrasana, L., Besson, J., Fond, C. \& Hochstetter, G. Experimental investigations and modeling of volume change induced by void growth in polyamide 11. Int. J. Solids Struct. 48, 2642-2654 (2011).

36. Poulet, P., Hochstetter, G., King, A., Proudhon, H. \& Laiarinandrasana, L. Observations by in-situ $X$-ray synchrotron computed tomography of the microstructural evolution of semi-crystalline Polyamide 11 during deformation. Polym. Test. (2016). doi:10.1016/j.polymertesting.2016.10.023

37. Pawlak, A., Galeski, A. \& Rozanski, A. Progress in Polymer Science Cavitation during deformation of semicrystalline polymers. Prog. Polym. Sci. 39, 921-958 (2014).

38. Humbert, S., Lame, O. \& Vigier, G. Polyethylene yielding behaviour: What is behind the correlation between yield stress and crystallinity? Polymer (Guildf). 50, 3755-3761 (2009). 